\title{
Historieta argentina La Nelly: construcción de un mundo social en el que la crisis es lo habitual
}

\author{
MHCJ no 7 | Año 2016 \\ Artículo no 9 (81) \\ Páginas 217 a 236 \\ mhjournal.org
}

\author{
Iván Lomsacov| ivanlomsacov@gmail.com \\ Universidad Nacional de Córdoba
}

Palabras clave

Historieta; Semiótica; Crisis; Argentina

Sumario

1.Introducción. 2. Metodología. 3. Resultados. 3.1. Descripción del objeto y la muestra. 3.2. Niveles de representación. 3.3. Punto de vista y formas de la mirada. 3.4. Ejes semánticos. 3.5. La voz narrativa. 3.6. Conclusiones. 4.Bibliografía.

\section{Resumen}

En este trabajo se analiza una selección de tiras de la historieta argentina de prensa diaria La Nelly mediante la extrapolación de conceptos y categorías de semiótica del cine al lenguaje propio del cómic y mediante la utilización de herramientas de la teoría literaria. El objetivo de este análisis es indagar en aspectos formales del artefacto narrativo utilizado en la obra y sentidos construidos por la misma para observar representaciones sobre la idiosincrasia argentina y sobre la Historia contemporánea del país, en procura de un objetivo mayor que excede a este trabajo puntual, parte de un proyecto más extenso y recién iniciado, que se propone analizar el mismo objeto desde distintas perspectivas teórico-metodológicas para observar los sentidos que la obra construye en torno a la idea de crisis. Este primer artículo de la serie produce algunas observaciones que estimulan a avanzar manteniendo como hipótesis de trabajo que La Nelly construye la crisis como algo habitual, como un estado permanente en Argentina y no como una situación de quiebre o pérdida momentánea de estabilidad.

\section{Forma de citar este artículo en las bibliografías}

Iván Lomsacov (2016): "Historieta argentina La Nelly: construcción de un mundo social en el que la crisis es lo habitual”, en Miguel Hernández Communication Journal, nº7, páginas 217 a 236. Universidad Miguel Hernández, UMH (Elche-Alicante). Recuperado el _ de de 20__ de: [ink del artículo en mhjournal.org] 


\section{Argentinian comic La Nelly: building a social world in which the crisis is the usual thing}

MHCJ no 7 | Año 2016

Artículo no 9 (81)

Páginas 217 a 236

mhjournal.org
Iván Lomsacov| ivanlomsacov@gmail.com

Universidad Nacional de Córdoba

\section{Keywords}

Comic; Semiotics; Crisis; Argentina

\section{Summary}

1.Introduction. 2. Methodology. 3. Results. 3.1. Description of the object and the sample. 3.2. Representation levels. 3.3. Point of view and look forms. 3.4. Semantic axes. Representation of characters. 3.5. Narrative voice. 3.6.Conclusions. 4. Bibliography.

\begin{abstract}
In this paper a selection of cartoon strips of the Argentinean daily newspaper "La Nelly" is analyzed by extrapolation of concepts and categories of semiotics of cinema to the own language of comics and using tools of literary theory. The purpose of this analysis in to inquire on formal aspects of narrative device used in this comic, and in senses built by this, to observe representations of Argentina's idiosyncrasies and about the contemporary History of this country, in pursuit of a larger purpose which surpasses this punctual work, part of a larger project that has just begun, whose purpose is to analyze the same object from different theoretical and methodological perspectives to observe the sense that this comic built around the idea of crisis. This first work of the serial makes some observations that encourage to keep as a working hypothesis that La Nelly builds the concept of crisis like a usual thing, like a permanent state in Argentina, and not like a break situation or momentary loss of stability.
\end{abstract}

\section{How to cite this paper in bibliographies}

Iván Lomsacov (2016): “Historieta argentina La Nelly: construcción de un mundo social en el que la crisis es lo habitual", en Miguel Hernández Communication Journal, nº7, páginas 217 a 236. Universidad Miguel Hernández, de de 20__ de: @ink del artículo en mhjournal.org] 


\section{Introducción}

Este trabajo se propone como una primera aproximación al objeto La Nelly, tira de historieta humorística de prensa argentina, dentro de un plan de abordajes, aún en fase inicial, del mismo objeto, basados en distintos recortes de corpus y mediante distintas perspectivas teóricometodológicas. En este trabajo en particular, mediante el análisis semiótico de aspectos formales del artefacto narrativo utilizado en la obra y de sentidos construidos en la misma, se pretende la indagación de, entre otras cuestiones, el sentido de crisis que la obra construye. Postulamos como hipótesis de trabajo que La Nelly construye la crisis como algo habitual, como un estado permanente en Argentina, como una característica idiosincrática del país, y no como una situación transitoria, de quiebre o alteración de una estabilidad o normalidad.

No conocemos por el momento otros trabajos académicos que hayan abordado este objeto, que consideramos de gran valor por su construcción de la cotidianeidad del escenario público argentino y de algunos estereotipos de ciudadanos del país. Así mismo, no hemos detectado hasta ahora la existencia de otros trabajos que hayan abordado el objeto Historieta mediante los conceptos que, desde la teoría semiótica del cine, tomamos para este trabajo. Sí es habitual la utilización de herramientas de la teoría literaria para el análisis de una historieta, lo que aquí también realizamos.

Y sí estamos al tanto de numerosos trabajos en progreso que, en el marco de un programa internacional de intercambio de investigadores propuesto por la fundación Marie SkłodowskaCurie para el período 2015-2018, abordan desde diversas perspectivas y a través de diversos objetos el tema Narrativas Culturales de Crisis y Renovación. El autor de este trabajo y el equipo de investigación al que pertenece; Estudios y Crítica de la Historieta Argentina, participan en dicho programa y están actualmente motivados, entre otras, por esa línea de trabajo.

\section{Método}

En este primer trabajo de una serie que recién inicia, analizamos un pequeño corpus de la tira de historieta elegida ejerciendo la extrapolación de conceptos y categorías propuestos para el abordaje de obras cinematográficas a una obra historietística, con la necesaria adaptación a las diferencias que el particular código de la Historieta impone. En concreto, aplicamos a nuestro objeto aportes teórico-metodológicos de dos autores italianos que abordaron la semiótica del cine; Francesco Casetti y Federico di Chio, y de dos autores franceses representativos de la teoría literaria que también fueron recuperados por algunos investigadores desde la semiótica del cine: Gerard Genette y Phillpe Hamon.

La obra que abordamos, La Nelly, es creación del guionista Rubén Mira y el humorista gráfico Sergio Langer, ambos argentinos, y apareció diariamente en el periódico Clarín, editado en Buenos Aires, desde septiembre de 2003. Primero y durante siete años, integró el conjunto de tiras y viñetas humorísticas que ocupa la contraportada de ese matutino; y desde 2010 hasta marzo de 2016 se publicó en el interior del diario, en una página de la sección La Ciudad. 
Por tratarse de un trabajo exploratorio con vistas a un desarrollo mayor, el corpus de análisis está limitado a dos conjuntos de tres tiras cada uno, representantes de dos arcos argumentales diferentes de la historieta objeto. El recorte intencional está constituido por algunas de las entregas de la tira seleccionadas para exhibir en la página web oficial de la tira como muestra de los respectivos arcos argumentales, con el fin de promocionar la venta de libros recopilatorios y otros productos comerciales vinculados a la obra.

Uno de los arcos argumentales que abordamos a través de las muestras de tres tiras, se titula "En el Planeta de las Antinomias". Según indica la firma del dibujante, estas tiras fueron realizadas durante el año 2004. En adelante, nos referiremos al recorte de tres tiras de dicho arco argumental analizado en este trabajo como Selección 1 (Figs. 01, 02 y 03). El otro arco representado en el corpus se denomina "Vacaciones en la cola del GNC". Por "cola", en Argentina se entiende fila, en este caso, la de espera para la carga de gas combustible para automotores. En este caso no existe, en nuestra selección, firma que nos indique año de realización. Sin embargo, otras tiras del mismo arco argumental, a las que accedimos con posterioridad a nuestro análisis a través del libro recopilatorio La Nelly. Argentinísima!!! (Langer y Mira, 2006) indican mediante firma que ese tramo de la serie de historieta se desarrolló en el año 2005. En adelante, nos referiremos a nuestro recorte de tiras de dicho arco como Selección 2 (Figs. 04, 05 y 06).

\section{Resultados}

\subsection{Descripción del objeto y la muestra}

La tira de historieta La Nelly está protagonizada por el personaje homónimo, apodo de Nélida "Nelly" Rocaforte. El personaje es una señora de barrio y de clase media de Buenos Aires, de alrededor de 60 años de edad, soltera y jubilada que, lejos de permanecer en su casa, vive diversas aventuras desopilantes en Buenos Aires, en Argentina y más allá, pero siempre con continuas referencias al universo sociopolítico argentino contemporáneo. Las tiras de Selección 1 (Figs. 01, 02 y 03) desarrollan un mayor despegue hacia lo fantástico de lo que prepondera en la obra, mayormente anclada en una ambientación de coordenadas realistas y cotidianas. Aquí la protagonista se encuentra en un planeta representado por superficies desiertas con cráteres y montañas en pico, y poblado por criaturas siamesas bicéfalas. Sin renunciar al despliegue de situaciones frenéticas que caracteriza a esta obra, las tiras de Selección 2 (Figs. 04, 05 y 06) ambientan los hechos en la cotidianeidad terrestre del Gran Buenos Aires; conglomerado urbano que abarca la Ciudad Autónoma de Buenos Aires, capital del país, y varias ciudades o partidos de la Provincia de Buenos Aires que la rodean.

\subsection{Niveles de representación}

En el cuarto capítulo de su libro Cómo analizar un film, Francesco Cassetti y Federico di Chio (1991: 124-125) proponen tres "niveles de representación", a los que entienden como "planos de funcionamiento" de la imagen fílmica. Uno es el "nivel de los contenidos representados en la imagen": escenario, objetos, personajes, su aspecto y características, sus acciones. Otro es el nivel 
"de la modalidad de representaciones de la imagen: la forma peculiar en que esos personajes, objetos y escenarios se nos presentan, a través de los diferentes encuadres, planos y otros recursos". Y el tercer nivel es "el de los nexos que, en la representación cinematográfica, unen a una imagen con otra que la precede o que la sigue", estableciendo relaciones que nos permiten registrar la transformación de los escenarios, los cambios de posición de los objetos y los comportamientos de los personajes.

A estos tres niveles que, como subrayan estos autores italianos, funcionan simultáneamente pero a la vez pueden percibirse como distinguibles, retomando la tradición conceptual de la teoría del cine los denominan respectivamente "nivel de la puesta en escena", "nivel de la puesta en cuadro" y "nivel de la puesta en serie" (1991: 126).

La puesta en escena, nos atrevemos a simplificar nosotros, es lo que allí hay. La puesta en cuadro determina, o está determinada, por el tamaño en que se muestra y la forma en que se ubica y se recorta lo que allí hay. Y la puesta en serie, volviendo a intentar nuestra propia explicación, es el conjunto de conexiones de lo que allí hay y cómo se ve con lo que allí había antes y cómo se veía, o con otros escenarios que se mostraron antes y lo que allí había y cómo se veía, y con lo que podría haber y verse de determinada manera en ese escenario o en otros que se presenten a posteriori.

Creemos que aplicar estos "niveles de representación" al análisis de la Historieta no resulta una decisión forzada, e incluso cobra especial importancia, dado que la misma es, como el Cine, un lenguaje para la narración secuencial con imágenes, aunque en este caso se trata de imágenes estáticas, que constituyen una secuencia más fragmentaria. Dificultada para representar transiciones o continuidades, como puede hacer el Cine con un plano secuencia, la Historieta necesita contar mediante "flashes" muy precisos, extremar lo juicioso de la selección de lugares, personajes y cosas que muestra así como la forma en que visualmente se los jerarquiza (puesta en escena y puesta en cuadro), recortando momentos y vinculándolos mediante permanentes elipsis (puesta en serie).

Esa economía rigurosa se experimenta de manera particular en el formato tira, obligado a la brevedad de la secuencia por lo acotado que resulta el espacio con el que cuenta para cada entrega: por lo general una tira, integrada tradicionalmente por una única línea de viñetas, está integrada por no más de tres o cuatro de ellas. Y las escasas veces en que ese número se supera, como el espacio físico para desplegar la tira sigue siendo muy acotado, las viñetas pierden ancho, con las limitaciones que eso implica para implementar encuadres abiertos y el despliegue de detalles.

En nuestro recorte de La Nelly, no obstante, la puesta en escena, la puesta en cuadro y la puesta en serie se construyen mediante una sucesión de planos generales que permite visualizar en todas las viñetas a todos los personajes presentes en la situación narrada, construir en cada una de esas viñetas una secuencia de diálogo con más de una intervención a cargo de diferentes personajes y 
mostrar en cada cuadro la "escenografía" o contexto, así como objetos narrativamente importantes, fundamentales para la acción, tales como un cohete en la Tira 3 de la Selección 1 (Fig. 03) o un ordenador y automóviles en las tiras de la Selección 2 (Figs. 04, 05 y 06); constituyendo así una gramática visual que casi no registra variantes en estos aspectos.
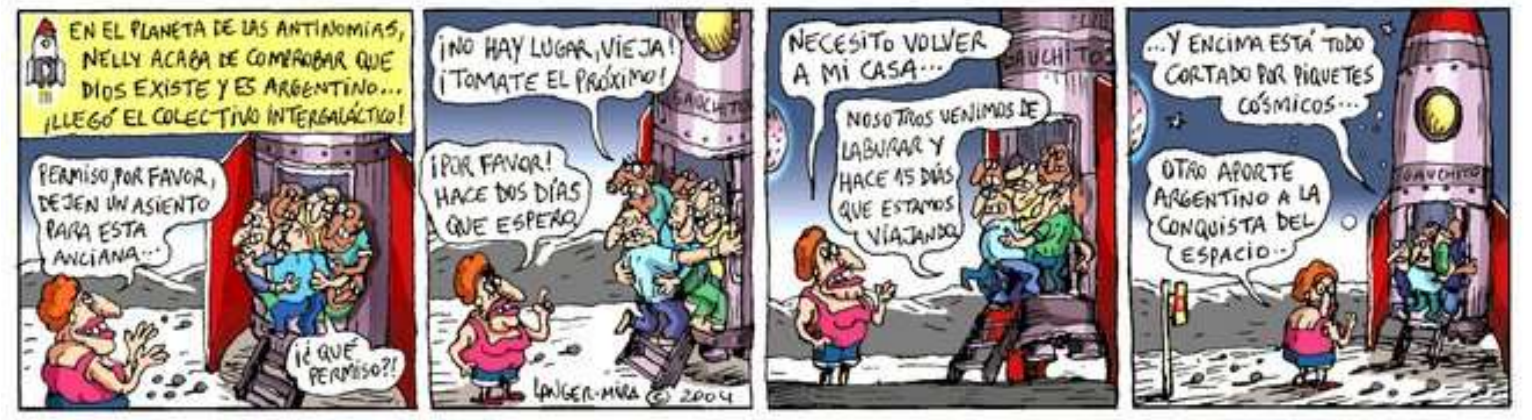

Fig. 03

En ese sistema de relato, la protagonista, Nelly, aparece visible en la gran mayoría de las viñetas. Las únicas excepciones son dos viñetas de la Tira 1 de la Selección 2 (Fig. 04) y otras dos viñetas de la Tira 3 de la misma selección (Fig. 06). En el primer caso, el personaje está ausente de la viñeta introductoria, porque aún no ingresó a la acción, y no se ve en la tercera y última viñeta pero sí está presente en ella a través de “su voz": el parlamento contenido en uno de los globos, remate de la tira, claramente le corresponde, lo que puede deducirse tanto del contexto y la continuidad lógica del discurso como por el recurso formal del rabo de globo que señala al vehículo en el que se vio a Nelly en las viñetas anteriores.

En el otro caso, Selección 2 Tira 3 (Fig. 06), la protagonista está ausente en la segunda y en la tercera viñeta de la tira por no tener línea de diálogo ni ser partícipe de una acción en esos dos momentos narrados, en los que interactúan exclusivamente otros dos personajes, también presentes en las dos viñetas restantes. Pero reaparece en la cuarta para dar pie el remate humorístico, en boca de un policía.
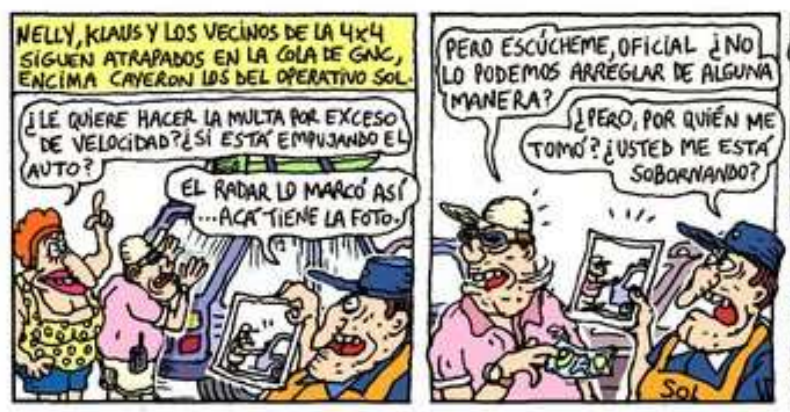
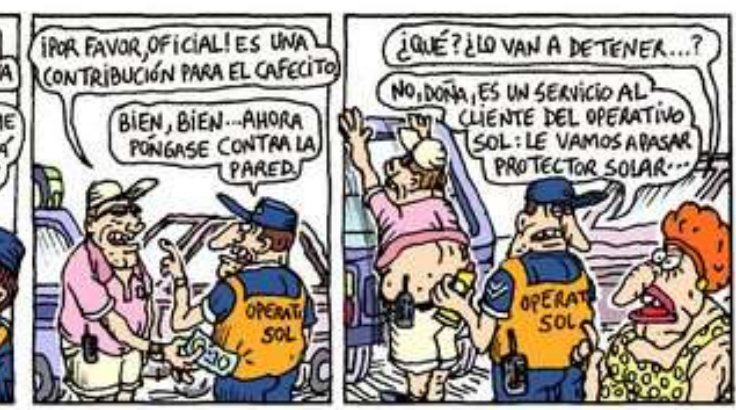

Fig. 06

En todo caso, las decisiones de puesta en cuadro en estas tiras parecen obedecer más a necesidades narrativas que a intencionadas operaciones retóricas: los encuadres generales se usan para desarrollar un intercambio de diálogo en cada viñeta, las ubicaciones de los personajes dentro de la viñeta van rotando de acuerdo al turno de habla. En la Historieta, la secuencia de 
esos turnos necesariamente responde a un código que hace corresponder la disposición visual del conjunto de los globos de diálogo con la secuencia temporal en la que se emite cada parlamento, y tal ubicación sistemática de cada globo condiciona en gran medida la ubicación del personaje dentro de la viñeta, lo que, por supuesto, no sucede en los relatos audiovisuales, en lo que el espacio no es tiempo, como sucede en cierta manera en la Historieta.

No obstante, esa opción por la preponderancia de los planos abiertos, que permite visibilizar permanente y simultáneamente a numerosos personajes, incluso personajes anónimos que serían el equivalente a los extras del cine, junto a no pocos elementos contextuales, puede interpretarse como una modalidad elegida para construir situaciones masivas y populares caóticas, enloquecidas, que hacen en mucho al tono de grotesco de conurbano bonaerense, referente al conglomerado Gran Buenos Aires, que caracteriza a la serie, aun cuando, momentáneamente, la acción se ambiente en otro planeta.

\subsection{Punto de vista y formas de la mirada}

En el sexto capítulo de su libro, Cassetti y Di Chio proponen como otro elemento para el análisis de un film "el punto de vista", explicando que "quien muestra lo hace, de hecho a partir de una perspectiva bien definida (...) y quien recibe debe, si no situarse en el mismo punto de observación que el destinador, por lo menos tener en cuenta esta parcialidad de su mirada" (1991: 232). En primer lugar, y pensándolo exclusivamente desde el destinador, el punto de vista es "el punto desde el que se capta concretamente la realidad presentada en la pantalla": desde dónde se mostrarán los escenarios, personajes y objetos.

Explican los autores que el punto de vista, "que señala el paso de un mundo simplemente filmable a un mundo tal como ha sido filmado", identifica a la vez una lógica de construcción y una clave de desciframiento y señalan que en ocasiones "puede encarnarse en la visión de un solo personaje: es lo que sucede en la cámara subjetiva, en el flash-back, en la representación de los sueños" (1991: 233-234). Aclaran, además, que si bien el punto de vista puede analizarse imagen por imagen, registrando la heterogeneidad de angulaciones y objetivos, también podemos observar una orientación general del film respecto a estas decisiones de perspectiva.

Siguiendo a Casetti y di Chio, el punto de vista puede entenderse en principio en un sentido puramente óptico, pero está acepción "perceptiva" va ligada a otras dos: "la cognitiva -la imagen, mostrando algunas cosas y no otras, selecciona rasgos y aspectos de lo visible, y así proporciona ciertas informaciones, evidencia ciertos datos- y la axiológica-epistémica": según cómo esté constituida, la imagen "expresa valores de referencia, ideologías de fondo, convicciones y conveniencias particulares". De modo que el punto de vista, explicitado mediante el mecanismo de "focalización", en tanto que selección y subrayado de cuanto se encuadra, "expresa más radicalmente un modo de captar y de comportarse, de pensar y de juzgar" (1991: 236 y ss.).

De las distintas formas de punto de vista, y de sus figuras portadoras, estos semióticos italianos derivan cuatro tipos de "actitudes comunicativas", "cuatro grandes tipos de mirada", incluyendo 
en la idea de "mirada" tanto el ver como el saber y el creer, que "nacen de distintas combinaciones de los factores comunicativos y de los distintos grados de explicitud que éstos asumen". Distinguen así cuatro configuraciones de la mirada: "la objetiva, la objetiva irreal, la interpelación y la subjetiva" (Ibíd., 1991: 246).

La mirada objetiva tiene "un punto de vista emisor y un punto de vista receptor que la estructuran globalmente, pero no tiene ninguno que proponga un punto personal en su interior", proponiendo una ilusión de neutralidad y naturalidad. En consecuencia, "el destinador se neutraliza, actuando sin mostrarse explícitamente y el destinatario se sitúa en una posición oculta, como un simple testigo" (Ibíd., 1991: 247).

La mirada objetiva irreal muestra porciones de la realidad "de modo anómalo (...) como signo de una intencionalidad comunicativa que va más allá de la simple representación”. Encuadres poco comunes "impiden la inmediata reconocibilidad de las cosas" y movimientos de cámara vertiginosos "trastornan el modo habitual de acercarse a las cosas". Este "subrayado extremo que convierte las presencias en explícitas" genera una identificación más explícita del destinador con la cámara (Ibíd., 1991: 247-248).

En la interpelación, la imagen presenta "un personaje, un objeto o una solución expresiva cuya función principal es la de dirigirse al espectador llamándolo directamente: es el caso de la voz over, de lo didascálico, de la mirada a cámara, etc.". Tales recursos explicitan claves del "proyecto comunicativo del film" manifiestan explícitamente al destinador y al destinatario, producen "un abandono momentáneo del plano de la narración y una apertura al plano de la comunicación" (Ibíd., 1991: 249-250).

Finalmente, la mirada subjetiva consiste en un desplazamiento de la narración hacia la pura perspectiva de los personajes: "todo cuanto aparece en pantalla coincide con lo que un personaje ve, siente, aprende, imagina, etc.”, lo que genera un espectador que “asume una posición, por así decirlo, activa", al hacerlo ingresar a la narración a través de los ojos, la mente y las creencias del personaje (Ibíd., 1991: 250-251).

Al extrapolar esas configuraciones al análisis de nuestra muestra de una historieta, nos incumben especialmente la primera y la tercera. Observamos que La Nelly está narrada preponderantemente como si se filmara con una "cámara objetiva", que propone la ilusión de igualdad entre destinador y destinatario frente a lo narrado: el destinador es testigo de lo mismo que el destinatario, sin veladuras evidentes. La escasa modulación a nivel de encuadres que anteriormente describimos, es funcional a esa retórica.

La constancia de los encuadres amplios es continuamente modulada por variantes moderadas en el grado de esa amplitud, como bajo la mirada de un zoom inquieto que, sin embargo, se prohíbe avanzar más allá de un plano medio, y por una notable variabilidad de enfoques que otorga 
dinamismo al relato y que, como ya hemos comentado, en gran parte se relaciona con la necesaria ubicación de los personajes según su turno de habla.

Sin embargo, tal variabilidad de puntos de vista encuentra límite en no abandonar el eje horizontal de la mirada: no hay aquí picados ni contrapicados, gran angulares ni otros enfoques que impliquen una perspectiva diferente a la habitual, anómala. $\mathrm{Y}$ aunque se detectan algunas pequeñas incoherencias formales, como modificaciones del tamaño de figuras que no responden proporcionalmente a modificaciones de encuadre y enfoque producidas, el raccord, es decir, la continuidad espacial o temporal correcta entre dos planos consecutivos, está construido con solvencia, en un montaje que asocia a las imágenes por transitividad: "una imagen está relacionada con otra por que representan distintos momentos de una misma acción" (Casetti y di Chio, 1991: 136).

Precisamente, otro de los elementos analizados en films por Casetti y di Chio que vamos a tener en cuenta en nuestras tiras de historieta es la construcción del tiempo, que establece la duración, una relación entre el tiempo de la historia, o acontecimiento relatado, y el tiempo del relato. Distinguen dos modalidades de intervención en dicha duración: "contracción” y "dilatación". La primera incluye dos formas: la elipsis y la recapitulación. Y como modos de dilatación, señalan la extensión (por expansión) y la pausa (por suspensión) (1991: 158-161). Y explican cómo tanto la puesta en escena y la puesta en cuadro como la puesta en serie "contribuyen a definir la sensación de duración”" (Ibíd., 1991: 155).

En las tiras de historieta que integran nuestra muestra no se registran otras formas de contracción ni de dilatación del tiempo más que las mínimas y obligadas elipsis entre viñeta y viñeta que toda historieta necesita, ya que en esta en particular cada una de las tiras narra un único acontecimiento ocurrido en un mismo espacio durante lapso de tiempo acotado y continuo, lo que acerca la duración construida en ellas a lo que los italianos categorizan como "duración natural relativa" (Casetti y di Chio, 1991: 163).

Otro de los aspectos referentes al tiempo contemplados en Cómo analizar un film es la "frecuencia", entendida como la cantidad determinada de veces que se representa lo que sucedió determinada cantidad de veces. De ello surgen cuatro tipo de frecuencias: simple, múltiple, repetitiva, e iterativa o frecuentativa. Los dos primeros son las más habituales: se representa una vez algo que sucedió una vez o se representa muchas veces algo que sucedió muchas veces, lo que nos mantiene "en el ámbito de la normalidad". (Ibíd., 1991: 161). Los restantes, en cambio, implican operaciones más complejas y por tanto explicitan más el accionar de un enunciador.

Retomando nuestra extrapolación, cada tira de La Nelly tomada para nuestro trabajo responde a una frecuencia del tipo simple, ya que cuenta una vez lo que pasó una vez. En ellas, además, el orden de las acciones es cronológico, sin recurso a flashbacks ni a flashforwards, lo cual colabora a la permanencia en "el ámbito de la normalidad", facilitando la construcción de una mirada objetiva. 
La "cámara objetiva" que predomina en estas tiras tiene como interesante excepción la interpelación a la que el enunciador recurre en el cierre de algunas de las secuencias. En la última viñeta de la Tira 1 de la Selección 1 (Fig. 01), por caso, el personaje central dirige su mirada, y por tanto su alocución, al lector. Se dirige a él, comparte de ese modo su reflexión final, o remate humorístico de la tira, y establece así con el enunciatario una complicidad, que rompe momentáneamente la burbuja ficcional, generando un efecto desficcionalizante, y fuerza el abandono transitorio de esa posición ajena a los hechos que hasta entonces se construye para el enunciatario.
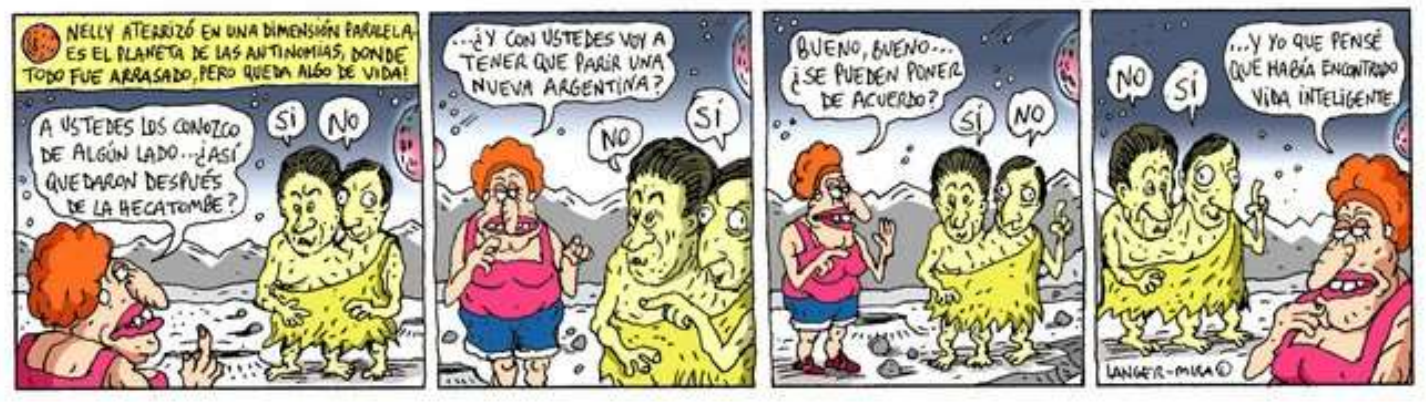

Fig. 01

En esos cierres de tiras, el lector se ve fugazmente un poco más involucrado en la situación y está momentáneamente junto a Nelly en "El Planeta de las Antinomias". Esta operación enunciativa es reforzada por la "puesta en cuadro", que ubica a Nelly en el ángulo inferior derecho de la viñeta, el más "cercano" a la mirada del lector, y recortada en un plano medio que aumenta la sensación de proximidad. El comportamiento cinético del personaje termina de construir la actitud inclusiva hacia el lector: la mano llevada hacia un costado de la boca en forma de barrera remarca que el comentario es compartido con el lector al tiempo que se lo vela a la percepción del otro personaje presente en la viñeta, porque además, mediante la ironía, se refiere negativamente a él. La protagonista está más "cerca" del lector que de la criatura con la que comparte esa entrega de la tira.

Algo similar, aunque formalmente algo diferente, ocurre al final de la Tira 3 de la Selección 1 (Fig. 03). Esta vez, la protagonista dirige su reflexión final "a cámara" mediante un giro completo de cabeza que realiza sin abandonar su posición de tres cuartos perfil trasero y permaneciendo en un encuadre de plano general que comparte con los demás personajes, pero en una ubicación centrada en cuanto al eje horizontal y más próxima "a cámara" que los pasajeros espaciales de la tira.

\subsection{Ejes de oposición}

Phillipe Hamon, desde la teoría literaria, en su artículo "Para un estatuto semiológico del personaje" (1977) propone analizar a los personajes de un relato clasificándolos a partir de una serie de ejes semánticos "fundamentales pertinentes (el sexo, por ejemplo) que permiten la estructuración de la etiqueta semántica de cada personaje (etiqueta (...) inestable y permanentemente reajustable por las transformaciones mismas del relato), y del conjunto del sistema" (Hamon, 1977: 7). El personaje "será entonces definido por un haz de relaciones de 
semejanza, de oposición, de jerarquía y de ordenamiento (su distribución) que contrae, sobre el plano del significante y del significado, sucesiva y/o simultáneamente, con los otros personajes y elementos de la obra". Hamon retoma esta propuesta de Todorov:

(...) descomponer cada imagen en rasgos distintivos, y ponerlos a éstos en relación de oposición o de identidad con los rasgos distintivos de los otros personajes del mismo relato. Se obtendría así una cantidad reducida de ejes de oposición cuyas diversas combinaciones reagruparían estos rasgos en haces representativos de los personajes (1977: 7).

Siguiendo esa línea, abordaremos los personajes a partir de algunos ejes de oposición que, a partir de Hamon, han sido aplicadas a obras cinematográficas y literarias, a partir de otros ejes que proponemos nosotros teniendo en cuenta particularidades de nuestro objeto. Uno de aquellos ejes ya utilizados con habitualidad plantea clasificar a los personajes como individual o colectivo. Pues bien, la protagonista y Klaus, "el bonista extranjero", clasifican fácilmente como personajes individuales, y los hombres trepados al cohete en la Tira 3 de la Selección 1 (Fig. 03), constituyen claramente un personaje colectivo, así como los turistas constituyen un personaje colectivo en las tiras de Selección 2 (Figs. 04, 05 y 06). Pero la dicotomía se topa en las otras tiras de Selección 1 con una opción interesante que la complejiza: uno de los seres siameses que pueblan "El Planeta de la Antinomias", el que aparece en la Tira 1 (Fig. 01), tiene en una cabeza la cara de Eduardo Duhalde, ex presidente argentino 2002-2003 y ex vicepresidente 1989-1995, y en otra, la cara de Néstor Kirchner, por entonces presidente de Argentina, habiendo sucedido a Duhalde.

Ante cada pregunta de Nelly, el ser reacciona con dos respuestas que se oponen entre sí: cada vez que la cabeza de Duhalde responde "Sí", la de Kirchner contesta "No", y viceversa. Según alude el cartucho de relator de la segunda tira analizada, ese ser es denominado "Eduardo Néstor", combinación de los nombres de pila de ambos políticos argentinos, y en una línea de diálogo de la tercera tira Nelly lo alude como "Los Duhalner", clara fusión de ambos apellidos. Esta criatura bicéfala de la Tira 1 (Fig. 01) no puede, pese a su unidad en un cuerpo, considerarse completamente como un personaje "individual", ya que reúne en sí dos identidades, que además se contradicen mutuamente en forma constante, manifiestan, precisamente, una de las antinomias que dan nombre al planeta. Pero tampoco puede clasificarse como un personaje colectivo.

Lo mismo podemos suponer que sucede con otro ser bicéfalo, que no aparece en imagen pero es mencionado en el cartucho de relator de la Tira 1 de esta Selección 1 (Fig. 01): "Cristina Hilda". Claramente podemos imaginar su condición de versión femenina de "Los Duhalder", portadora de los rostros de Cristina Fernández de Kirchner, esposa de Néstor Kirchner, por entones primera dama, senadora nacional y ex diputada nacional, e Hilda González de Duhalde, esposa de Eduardo Duhalde y por entonces diputada nacional, en un mismo cuerpo (y podemos comprobar esa suposición viendo otras tiras en el libro compilatorio La Nelly. Argentinísima!!!, aunque esas tiras exceden al corpus recortado para este trabajo). 
En cambio, en la Tira 2 de la Selección 1 (Fig. 02), Nelly interactúa con otro ser bicéfalo que en ambas cabezas tiene la misma cara: la de Carlos Menem, ex presidente argentino 1989-1995 y 1995-1999. Este personaje, a diferencia del anterior, sí puede ser considerado como un individuo: las cabezas son copias iguales de una misma identidad, y emiten el mismo parlamento al unísono, sin establecer discordancia alguna, manteniendo unidad interna, lo que claramente refuerza su poder. El mismo poder que el personaje exhibe en su gestualidad facial, firme y severa, con algo de malignidad, muy distinta a los gestos desconcertados de "los Duhalner" de la tira anterior, y que manifiesta al cierre de esa entrega al mostrar su camiseta promocional de campaña electoral para 2007.
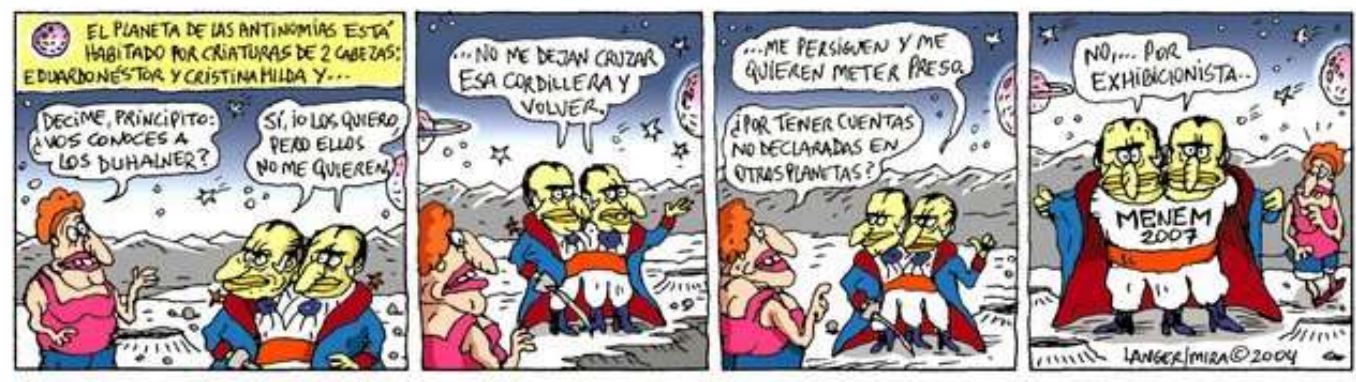

(Fig. 02)

No podemos obviar allí la retórica irónica ejercida por el enunciatario, que otorga esa actitud arrogante y ese plan de postularse a elecciones a ese personaje que es absolutamente referencial de Menem, que un año antes de publicarse la tira se había retirado de las elecciones presidenciales 2003 antes del ballotage tras haber perdido en primera vuelta por ligero margen frente a un todavía poco conocido Néstor Kirchner. Cabe subrayar que la realización y publicación de estas tiras data del año 2004, momento muy próximo a la asunción de Kirchner como presidente en reemplazo de Duhalde.

En este punto, no hay que pasar por alto una intertextualidad que la obra teje. El humanoide con doble cara de Carlos Menem que habla con Nelly en la Tira 2 de la Selección 1 (Fig. 02) viste como el personaje literario El Principito y es interpelado por Nelly explícitamente con el mote de "Principito". El uso de esta caracterización de vestuario y denominación podría obedecer simplemente a la tentación de aprovechar lúdicamente la referencia a un personaje icónicamente ligado al tipo de ambientación planetaria construida en estas tiras. Pero hay algo más: anulado ya, por efecto de la paradoja irónica, el valor de bondad que caracteriza al niño creado por SaintExupéry, ese dialogismo le otorga al personaje un status nobiliario y de propietario del planeta que aporta a la construcción de ese personaje referencial de un ex presidente que gobernó diez años a fuerza de decretos-ley y tomándose ciertas licencias ligadas al lujo, propias de un rey.

Planteemos ahora otro eje que habitualmente merece atención: poderoso/no-poderoso. Al aplicarlo a nuestra Selección 1 (Figs 01, 02 y 03), podemos volver a la diferencia que al respecto se construye entre los dos seres bicéfalos que se ven en estas tiras ambientadas en "El Planeta de las Antinomias": el poder del Menem "Principito" de dos cabezas frente al no-poder del/los "Duhalner", que se anulan entre sí contradiciéndose permanentemente. 
Este sentido, investido en 2004, pierde sintonía con la realidad socio-histórica en una lectura más contemporánea, a la luz de la Historia que transcurrió después, con el crecimiento del poder de Néstor Kirchner como presidente, la casi total desaparición de la escena política de Eduardo Duhalde, la casi silenciosa actividad de Carlos Menem en el Senado de la Nación votando a favor de proyectos legislativos claves para la gestión kirchnerista o simplemente ausentándose a las sesiones, y las sentencias judiciales contra el mismo Menem por las acusaciones que pesaban contra él por contrabando de armas desde los años 90.

Pero en las condiciones socio-históricas del momento de realización de las tiras analizadas, la construcción resulta sugerente, y llama a dar un próximo paso, que sería analizar las tiras en la atmósfera semiótica de los ejemplares del diario Clarín en que aparecieron, vinculándolas a titulares, noticias y notas de opinión del medio. Así mismo, resulta motivador para iniciar el análisis de un corpus mayor de tiras, abarcativas de distintos momentos socio-políticos que sucedieron a esos primeros meses de gobierno kirchnerista.

En cuanto a ejes oposicionales nuevos, que nosotros proponemos para clasificar los personajes de esta historieta, comenzamos con la dicotomía argentinos/no argentinos. En Selección 2, la distinción es sencilla. En la Tira 1 (Fig. 04), todos los personajes pueden ser clasificados como argentinos menos Klaus, presentado como "el bonista extranjero" en el cartucho de relator al comienzo de la tira, y a quien Nelly explica: "¿Te das cuenta, Klaus? Los argentinos la tenemos clara”. En las restantes tiras de la Selección 2 (Figs. 05 y 06), los personajes son aludidos como "Los turistas", "los vecinos de la 4x4", o son policías, y no tenemos elementos que permitan considerarlos no-argentinos.
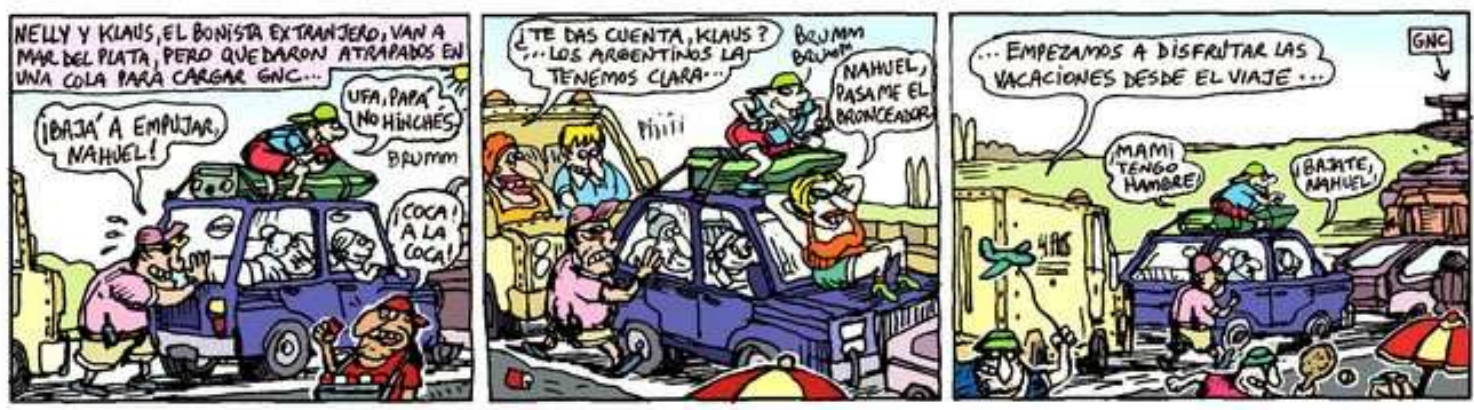

Fig. 04

En cambio, ese mismo eje semántico se complejiza al aplicarlo a la Selección 1: Los seres bicéfalos tienen las caras de Duhalde, Kirchner y Menem, y Nelly los interpela así: “¿Y con ustedes voy a tener que parir una nueva Argentina?”. ¿Implica eso que tales personajes son argentinos, aunque sean criaturas fantásticas y habiten otro planeta? ¿O es necesario plantear aquí un eje humanos/no-humanos o terrestres/extraterrestres? ¿Pueden ser ellos argentinos nohumanos, argentinos extraterrestres o argentinos de otra dimensión? 
En la Tira 3 (Fig. 03) de la misma selección, que mediante varios procedimientos homologa un cohete a un ómnibus, la manera en que personajes anónimos de anatomías humanas normales se disponen a viajar en un cohete, amuchados y montados incluso sobre la escalera exterior de acceso, puede ser reconocida por lectores argentinos como caricaturescamente representativa de las habituales precariedades del transporte público automotor de su país, el "colectivo". También pueden sentirse identificados con esas circunstancias lectores de otros países latinoamericanos o incluso de otros países del llamado Tercer Mundo. Sin embargo, al final de la tira Nelly, acota: "Otro aporte argentino a la conquista del espacio", en otra manifestación de la retórica irónica del enunciador, conectada con el texto de relator ubicado en la primera viñeta: "En el Planeta de las Antinomias, Nelly descubre que Dios existe, y es argentino...”.

Además, los dichos de los pasajeros; “...hace 15 días que estamos viajando.”, así como las intervenciones dialogales de Nelly; “...hace dos días que espero.”, aluden a la demora del medio de transporte en cuestión, que puede relacionarse con el sentido común atribuye, a veces estereotipadamente, al transporte colectivo en países como Argentina y similares: la escasa e impredecible frecuencia de sus servicios.

Y el texto de diálogo con el que un pasajero alude a una de las causas de la demora en la última viñeta recorta más aún el marco interpretativo de este relato: “....encima está todo cortado por piquetes cósmicos". Los piquetes, en el sentido de "pequeño grupo de personas que exhibe pancartas con lemas, consignas políticas, peticiones, etc.”, que incluye como alternativa el Diccionario de la Real Academia Española, fueron, bajo la modalidad de interrupción total o parcial del tránsito automotor en carreteras, una forma característica y frecuente de la protesta social en Argentina durante los años 90 y comienzos de la década siguiente.

Consideramos que esos elementos van construyendo una alegoría satírica de Argentina en la que un fantástico "Planeta de las antinomias", aunque pertenezca a "una dimensión paralela" que ostenta como única ambientación un desértico paisaje espacial poblado de cráteres y una permanente noche cósmica, funciona como otra Argentina: exhibe algunos de los problemas que este país tiene como sociedad, característicos de una situación crisis. Analizaremos ahora espacio y tiempo con la misma modalidad que abordamos personajes, mediante ejes semánticos, que nos permiten organizar esas dimensiones de manera especialmente interesante.

En el arco argumental representado en nuestra Selección 1, disparado hacia el género de ciencia ficción, los hechos narrados transcurren, según comunica el cartucho de texto de relator presente en la Tira 1 (Fig. 01), “en una dimensión paralela”, lo que nos permite proponer el siguiente eje: dimensión habitual/dimensión paralela. La idea de dimensión involucra a la vez tiempo y espacio, de modo que este eje es válido para ambos aspectos.

Pero además, en esa dimensión paralela, según indica el primer parlamento de la protagonista en la misma Tira 1 (Fig. 01), ocurrió una hecatombe (o una crisis terminal, anotamos), pensando en nuestro propósito mayor, y retomaremos esto pronto, que transformó el estado de las cosas, lo 
cual traza un eje pasado/presente para organizar el tiempo: un pasado en el que el holocausto aún no ocurrió y un presente en el cual, volviendo al relator, "todo fue arrasado, pero queda algo de vida". Y esa vida son las criaturas siamesas bicéfalas, en este caso el personaje doble que referencia a Duhalde y Kirchner, que antes analizamos, cuya curiosa conformación física se debe, según sugiere la pregunta retórica que Nelly formula en la primera viñeta, a los efectos de la hecatombe (Fig. 01).

No dejemos de apuntar que, en la Argentina de 2004, remitir a una hecatombe a la que sobrevivió un personaje que, como signo, tiene por significante las caras de Duhalde y Kirchner, nunca podía dejar de remitir a la gran crisis argentina de diciembre de 2001 (hiperinflación, "corralito" o retención de los ahorros de los ciudadanos, violentas represiones callejeras, repentina renuncia del presidente, sucesión de varios presidentes previsionales más en pocos días, default, sumergimiento de gran parte de la población bajo la línea de pobreza, etc.) tras la cual quien quedó instalado como presidente durante un año y medio fue Duhalde y quien lo sucedió fue Kirchner. De hecho, en la segunda viñeta Nelly habla con incredulidad de tener que "parir una nueva Argentina" con esos personajes que son y no son uno (Fig. 01). Esa idea de parto de un país nuevo, expresada con ironía en aquellas condiciones de producción, no puede dejar de vincularse al proceso de recuperación que habrían encarnado esos dos presidentes tras aquel momento bisagra, a partir de 2002.

Esas disidencias permanentes entre dos cabezas de un mismo cuerpo en un contexto de recuperación (o renovación, podríamos decir siguiendo el término utilizado por el mencionado programa impulsado por la fundación Curie), cobran sentido al recordar la transición del gobierno del justicialista Duhalde al del justicialista Kirchner. De alguna manera, el primero habilitó al segundo su llegada al poder, al renunciar a su cargo antes del plazo estipulado. Pero luego Duhalde expresó numerosas críticas a la gestión presidencial de Kirchner, a medida que este sorprendía con medidas progresistas, más parecidas al justicialismo original, de Perón, que al justicialismo tibio que Duhalde representó durante su corta presidencia y al justicialismo neoliberal que Duhalde integró como vice-presidente de Menem.
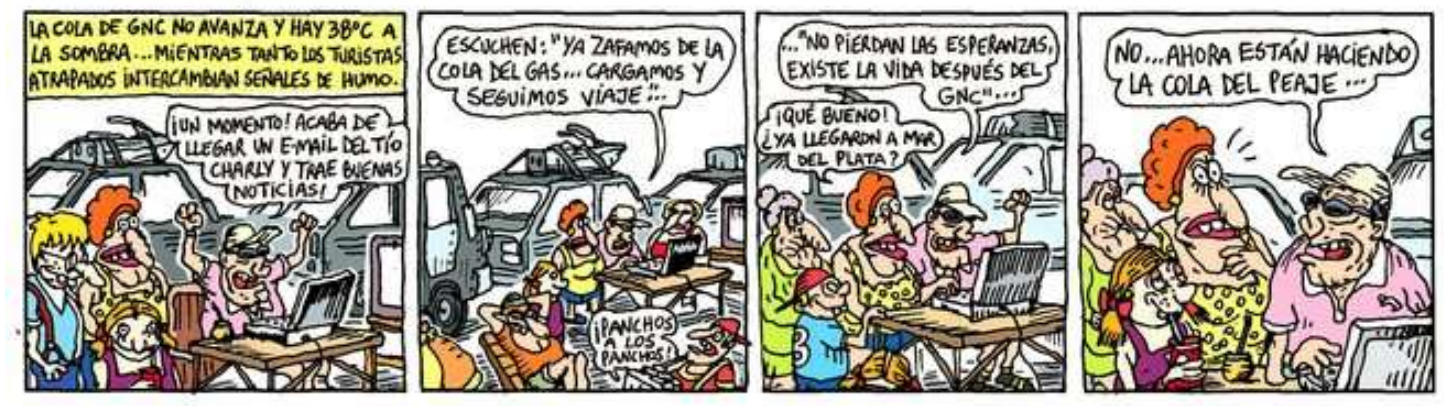

Fig. 05

Ese eje semántico también puede usarse no solo al interior de una de las selecciones, sino también para comparar una selección de tiras con la otra. En la Selección 1, el espacio es extraterrestre y en la Selección 2 es terrestre. Sin embargo, en la Selección 1 algunos elementos conectan con el espacio terrestre, que prácticamente resulta equivalente a argentino: el cartel de 
parada de ómnibus, el comportamiento de los pasajeros del cohete similar al comportamiento de los pasajeros de los transportes ómnibus argentinos, el nombre del cohete: "Gauchito" (diminutivo de gaucho, término que génerica y tradicionalmente identifica en Argentina, Uruguay y sur de Brasil al habitante de las llanuras ganaderas abocado a tareas rurales, el equivalente del "vaquero" norteamericano, pero también expresión usada en sentido figurado para referirse a alguien amable y generoso, propenso a realizar favores), su jerga y referencias socioculturales como "laburar" (trabajar), "piquetes" (cortes realizados en la circulación vehicular de una carretera como medida de protesta, mediante la presencia física de los manifestantes sobre la cinta asfáltica y el montaje de barreras, muchas veces dotadas de fuego mediante la incineración de neumáticos), y las caras de presidentes argentinos en las cabezas de los seres bicéfalos.

Sin embargo, también las tiras de la Selección 2 desarrollan situaciones absurdas, desaforadas, como pertenecientes a un mundo fantástico, pese a estar ambientadas en la cotidianeidad terrestre y argentina: los turistas en tránsito comienzan a realizar acciones vacacionales, tales como acelerar la moto de agua sobre el portaequipaje del vehículo, tomar sol sobre el capó, armar la mesita de camping en la banquina, mientras permanecen varados en una extensa fila de automóviles para cargar combustible; incluso un policía, en lugar de multar a un conductor, retribuye la coima que este le da, untándole protector solar en la espalda.

\subsection{La voz narrativa}

Desde la Teoría Literaria, el autor francés Gérard Genette dedica la mayor parte de su libro Figuras III (1987) a desarrollar su propuesta de análisis del "discurso del relato". Y destina el punto 5 de ese desarrollo a analizar las posibilidades que existen en torno a "la voz", entendida como la "identidad del narrador" (1987: 242), teniendo cuenta elementos como el tiempo de la narración y los niveles narrativos. Uno de los aspectos que Genette considera en su análisis de la voz es el "tiempo de la narración", entendido como la posición relativa de la instancia narrativa respecto de la historia narrada. Con tal posición como criterio, el autor francés distingue cuatro tipos de narración: ulterior, anterior, simultánea e intercalada.

Ante tal clasificación, el discurso de narrador de esta historieta puede considerarse como una narración de tipo simultánea: "relato en el presente contemporáneo de la acción" (1987: 274), en el que "la coincidencia rigurosa de la narración y la historia elimina toda especie de interferencia y de juego temporal". Ya hemos visto como la gramática narrativa de esta obra carece del recurso a flashbacks, flashforwards u otras alteraciones a la cronología. Y si bien la síntesis de los hechos ocurridos en entregas anteriores que el relator realiza en los cartuchos de texto específicos requiere de algunos verbos conjugados en pasado, tales verbos remiten fugazmente y sin desarrollo de acciones mostradas, dibujadas, a un pasado inmediato, mientras que son las conjugaciones en presente las que predominan en esas contextualizaciones que permiten comprender más cabalmente el sentido de los hechos narrados en la nueva entrega.

$\mathrm{Al}$ margen de tal simultaneidad, quien narra está construido como alguien distinto de cualquier actante de esta realidad ficcional, protagonista incluida. A nivel verbal, en la mayoría de estos 
cartuchos de relator las acciones de Nelly y los demás personajes aparecen narradas en tercera persona. A su vez, en su conocimiento cabal de los sucesos anteriores y de detalles irrisorios de las situaciones presentes, como el que explicita en Selección 2 Tira 2 (Fig. 05): "hace 38 grados a la sombra", el narrador manifiesta una omnisciencia que también lo coloca en un nivel extradiegético.

Esa construcción se refuerza a nivel visual: los cartuchos ostentan un estatus diferenciado de los globos de diálogo emitidos por los personajes, protagonista incluida, no solo por su forma; rectangular y sin cola frente a la curvatura y la cola de los globos, dirigida a personajes puntuales, sino también por el código de color: casi todos esos cartuchos son amarillos y algunos son lilas, mientras que los globos de diálogo siempre son blancos. Tal codificación gráfica otorga un estatus diferencial a esos textos de relator, los ubica en un plano diferencial a la palabra de todos los personajes, incluso la protagonista. Así, la voz de quien narra en La Nelly se construye como la voz de alguien externo al universo ficcional relatado, como externo es también, excepto en las escasas instancias que oportunamente señalamos, el destinatario, quien observa ese universo desde afuera.

\subsection{Conclusiones}

El análisis del corpus que hemos realizado desde herramientas de semiótica del cine y teoría literaria nos ha servido para observar varias cuestiones. Entre ellas, algunas cuyo valor nos queda pendiente considerar a la luz de futuros trabajos con el objeto Historieta. Otras, en cambio, se vinculan directamente con la hipótesis de trabajo que planteamos al comienzo de este trabajo y que por tanto mantendremos en futuros análisis de otros recortes de corpus (por un lado más extensos, y por otro constituidos por tiras creadas y publicadas durante los años siguientes), de la misma obra, a realizar con las mismas herramientas y también desde otra perspectiva teóricometodológica.

Hemos señalado cómo una puesta en escena, una puesta en cuadro y una puesta en serie que se construyen mediante una sucesión de planos generales facilitan la narrativización de escenas de masa al aire libre de tono desaforado pero siempre vinculadas a elementos culturales característicos de la cotidianeidad argentina, o al menos granbonaerense y de otras grandes urbes del país. Y cómo esto se construye así tanto cuando el mundo social representado es la realidad habitual (Selección 2, figuras 04, 05 y 06) como cuando lo es una "dimensión paralela" extraplanetaria (Selección 1, figuras 01, 02 y 03), que se presenta así como una alegoría fantástica de Argentina, que es fortalecida por referencias interdiscursivas a la realidad política de la historia argentina contemporánea.

Vimos también que en cuanto al punto de vista, que importa en su sentido cognitivo y axiológicoepistémico y no solo en su sentido puramente perceptivo, una narración realizada casi exclusivamente con la modalidad de objetiva propone una mirada habitual compartida por destinador y destinatario, sin posiciones inusuales o "privilegiadas" para observar lo narrado, retórica visual que es reforzada por la constancia de encuadres abiertos que acabamos de 
mencionar. Algo muy distinto a lo que propondría una mirada objetiva irreal, cuyos encuadres y angulaciones anómalos modificarían la forma "normal" de percibir las cosas, dificultando que fuera reconocidas como cosas habituales.

Así mismo, observamos que la construcción del tiempo de la narración, con un raccord que resulta coherente a un montaje por transitividad, con una ausencia de grandes intervenciones en la cronología y en la duración, que se constituye como natural relativa, colabora con esa proposición de "normalidad".

En La Nelly, el delirio, el grotesco, lo frenético, está en las situaciones mismas, en los universos que relata, y no en cómo las relata. No resulta necesario subrayar con una mirada anómala las "anomalías" que el mundo social construido por esta obra ya tiene. No hace falta una mirada "loca" para ver este mundo "loco"; alcanza con observarlo desde la altura de los ojos, sin perder la horizontalidad, y en plano general, para no perder de vista el conjunto.

Y eso propone el enunciador al enunciatario: una mirada de testigo privilegiado, pero externo a los hechos, que no pertenece ni se involucra, que no mira desde abajo porque no conoce ese lodo, pero que tampoco mira desde arriba porque no juzga; y que no se detiene en detalles, sino que mayormente observa en plano abierto, como esas cámaras de vigilancia urbanas emplazadas en la ciudad que registran escenas muy generales al ejercer un monitoreo visual permanente y cada vez más omnipresente de la vida urbana en reacción ante un estados de inseguridad (inseguridad urbana y su contraparte de vigilancia exacerbada a través de cámaras, que en su momento se plantearon como consecuencia de una situación de crisis, momentánea, y luego se instalaron como característica permanente de la vida cotidiana en los conglomerados urbanos de Argentina).

Y consideramos que todo ese artefacto narrativo formalmente "normal" actúa en servicio de una naturalización de las situaciones narradas, que desde afuera de esa mirada no pueden dejar de verse como poco "normales", como críticas.

De tal manera, en las tiras seleccionadas de la obra analizada se ve, se propone ver, "con normalidad" una realidad extraterrestre post apocalíptica (posterior a una crisis terminal), a la que se identifica como argentina tanto mediante menciones lingüísticas explícitas como en la reproducción de estereotipos y pautas culturales (algunos de ellos vinculados situaciones que en otros países serían consideradas propias de una crisis y en Argentina son habituales, como la escasez, demora y superpoblación del transporte público masivo) y la introducción de referencias políticas nacionales, un mundo social en el que la responsabilidad de una recuperación ulterior a un gran quiebre parece estar a cargo de una entidad escindida, cuya contradicción permanentemente la vuelve infecunda, como infecundos son los animales híbridos. 
Y también con la mirada habitual se ve, se propone ver, un atascamiento automotriz en una carretera que dura días con los vehículos casi inmóviles en espera del turno para cargar el combustible que permita llegar al destino vacacional (¿crisis energética, o habitual ineficacia e imprevisibilidad en la provisión de un servicio? ) y la fácil adaptación a tal situación de los ciudadanos atascados, quienes en ese mundo social momentáneamente constituido reproducen tanto parte del comportamiento que tendrían en la excepcionalidad periódica del veraneo como conductas que nuestra sociedad argentina exhibe con excesiva habitualidad: infracción de tránsito fraguada por la autoridad, ofrecimiento de coima por parte del infractor y aceptación complacida de tal coima por la misma autoridad acompaña de actitud servil hacia el infractor que aporta dinero ilegalmente. La capacidad de los personajes para ajustarse velozmente a una realidad inusual, para reaccionar con flexibilidad a la emergencia de un momento complicado, creemos, sigue construyendo en el discurso de esta historieta una población habituada a esas interrupciones en el camino hacia su horizonte de expectativas, capaz de moverse en la crisis como en su ámbito natural, como pez en el agua.

\section{Bibliografía}

CASETTI, F. y Di Chio, F. (1991). ¿Cómo analizar un filme? Paidós: Barcelona/Buenos Aires.

GENETTTE, G. (1989). Figuras III. Barcelona: Lumen.

HAMON, P. (1977). "Para un estatuto semiológico del personaje". En Barthes, Roland et al, poétique du récit. Págs. 115-180. París: Seuil. Traducción de Danuta Teresa Mozejko de Costa. Mimeo: Universidad Nacional de Córdoba.

LANGER, S. y Mira, R. (2004). La Nelly. Recuperado de: http://www.lanelly.com/arg-base.htm. Consultado el 18 de febrero de 2016.

LANGER, S. y Mira R. (2006). La Nelly. Argentinísima!!! Buenos Aires: Del Nuevo Extremo. 


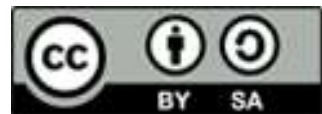

Licencia Creative Commons

Miguel Hernández Communication Journal

mhcj.es

Forma de citar este artículo en las bibliografías

Iván Lomsacov (2016): "Historieta argentina La Nelly: construcción de un mundo social en el que la crisis es lo habitual", en Miguel Hernández Communication Journal, nº 7, páginas 217 a

236. Universidad Miguel Hernández, UMH (Elche-Alicante). Recuperado el__ de de 20__ de: @ink del artículo en mhjournal.org] 